\title{
Death Temporally Related To the Use of A Beta Adrenergic Receptor Antagonist In Cocaine Associated Myocardial Infarction
}

\author{
Fareed $N$ Fareed, $M D^{a}$, Gar M Chan, $M D^{b}$, Robert S Hoffman, $M D^{c}$
}

aColumbia University Medical Center, NY, NY, USA

bNorth Shore University Hospital, Manhasset, NY, USA

cNew York City Poison Control Center, NY, NY, USA

\begin{abstract}
Introduction: Although it is commonly stated that the use of beta adrenergic receptor antagonists is contraindicated in patients with cocaine toxicity, actual clinical evidence of harm is lacking. This case helps to highlight the risks of beta adrenergic receptor antagonists in patients with chest pain associated with cocaine use.

Case Report: A 54-year-old man was brought to the emergency department (ED) complaining of chest pain after using approximately 1 gram of intranasal cocaine. Aspirin and nitroglycerin spray relieved his pain. Although he remained pain free, tachycardia persisted despite $15 \mathrm{mg}$ of diazepam intravenously. Nearly two hours after presentation, a total of 5 mg of metoprolol was given for persistent tachycardia (115/minute) and an elevated troponin. Shortly thereafter, the patient complained of crushing substernal chest pain, developed pulseless electrical activity, and could not be resuscitated.

Discussion: The administration of beta adrenergic receptor antagonists exacerbates cocaine-induced lethality in animals. In humans given smaller doses of cocaine, beta adrenergic receptor antagonists exacerbate coronary vasoconstriction. Both effects are presumed to occur through unopposed alpha adrenergic receptor agonism. Despite these data, actual cases describing adverse effects in cocaine users given beta adrenergic receptor antagonists are uncommon. This case supports the potential lethality of a cocaine-beta adrenergic receptor antagonist interaction.
\end{abstract}

\section{INTRODUCTION}

Cocaine use is a recognized risk factor for myocardial ischemia and infarction [1]. Following cocaine use, chest pain and other complaints suggestive of coronary ischemia are among the most common complaints of patients presenting to emergency departments [2]. Furthermore, cocaine use has been estimated to cause about one fourth of all myocardial infarctions in patients 45 years of age and younger [3].
Given the evidence to support the use of beta adrenergic receptor antagonists in patients with non-cocaine related myocardial injuries, regulatory agencies and multiple care guidelines have aggressively promoted the early use of beta adrenergic receptor antagonists in patients with acute coronary syndromes $[4,5]$. Since, by comparison, the evidence that contraindicates the use of beta adrenergic receptor antagonists in patients with cocaineassociated myocardial injury and ischemia is limited, many patients with known or unknown use of cocaine may receive beta

Keywords: cocaine, myocardial infarction, beta adrenergic receptor antagonist, adverse drug reaction Notes: An abstract of this case was presented at the 2005 North American Congress of Clinical Toxicology. There was no outside funding of any kind used for this study.

Corresponding Author: Robert S. Hoffman, 455 First Avenue Room 123, New York, NY, 10016. Email: bobhoffmd@gmail.com 
adrenergic receptor antagonists when hospitalized for acute coronary syndromes.

This case report reinforces the potential risk of beta adrenergic receptor antagonist therapy in cocaine-associated myocardial injury.

\section{CASE REPORT}

A 54-year-old man was brought to the emergency department (ED) complaining of a three-hour episode of chest pain the morning of admission. His past medical history was significant for daily use of both cigarettes and cocaine and a questionable history of untreated hypertension. He reported that the pain began approximately 3 to 4 hours earlier after he had used approximately 1 gram of intranasal cocaine over an unspecified time period. He described the pain as a midsternal, pressure-like pain that radiated to his mid-back and was associated with nausea and vomiting. The pain was exacerbated by physical activity and completely relieved following a single nitroglycerin spray and 162 $\mathrm{mg}$ of aspirin given by the paramedics en route to the ED. The patient related that over the previous six days he had similar symptoms that were self-limited, of shorter duration, and that he had experienced orthopnea and paroxysmal nocturnal dyspnea.

On presentation to the $\mathrm{ED}$, the patient was pain free. His vital signs were as follows: blood pressure, 145/95 mm Hg; pulse, 114/min; respirations, 20/min; temperature, 96.8 oF; and room air pulse oximetry, $97 \%$ saturation. He had no distress, and he was alert and oriented in all three spheres. Pertinent physical findings included normal papillary size and reactivity, mild jugular venous distension, symmetrical pulses, a chest that was clear to auscultation, rapid but normal heart sounds without murmurs, rubs, thrills or gallops, a soft abdomen with normal bowel sounds, no hepatosplenomegaly, masses or tenderness, and no pedal edema.

Oxygen was administered via nasal cannula and an electrocardiogram was obtained (Figure 1). The patient was given a total of $15 \mathrm{mg}$ of diazepam intravenously over 25 minutes with no change in his vital signs: blood pressure was 141/93 mm Hg; and pulse was 115/minute. A complete blood count showed a white blood cell count of $14,000 / \mathrm{mm}^{3}$, a hematocrit of $39 \%$, and 386,000 platelets $/ \mathrm{mm}^{3}$. A basic metabolic profile showed the following: sodium, $138 \mathrm{mEq} / \mathrm{L}$; potassium, $5.0 \mathrm{mEq} / \mathrm{L}$; chloride, 102 $\mathrm{mEq} / \mathrm{L}$; bicarbonate, $23 \mathrm{mEq} / \mathrm{L}$; blood urea nitrogen, $29 \mathrm{mg} / \mathrm{dL}$; creatinine, $1.4 \mathrm{mg} / \mathrm{dL}$; and glucose, $126 \mathrm{mg} / \mathrm{dL}$. The troponin was elevated at $1.51 \mathrm{ng} / \mathrm{mL}$ (normal $<0.07 \mathrm{ng} / \mathrm{mL}$ ). A urine toxicology screen for drugs of abuse was positive for cocaine and benzodiazepines (given in the ED), and negative for amphetamines and other drugs of abuse. A portable chest radiograph, interpreted by the radiologist, demonstrated cardiomegaly with mild congestive changes (Figure 2).

One hour and fifty-five minutes after triage, the patient was given $325 \mathrm{mg}$ of aspirin orally. Metoprolol, $2.5 \mathrm{mg}$ IV, was given for persistent tachycardia (pulse 115/minute). No change in vital signs was recorded and a second $2.5 \mathrm{mg}$ dose of metoprolol was administered 5 minutes later. Ten minutes following the second dose of metoprolol, the patient complained of crushing substernal chest pain (10/10 in intensity) and was diaphoretic and nauseated. Shortly thereafter he became pale and unresponsive with a systolic blood pressure of $50 \mathrm{~mm} \mathrm{Hg}$ and a pulse of 120/minute.

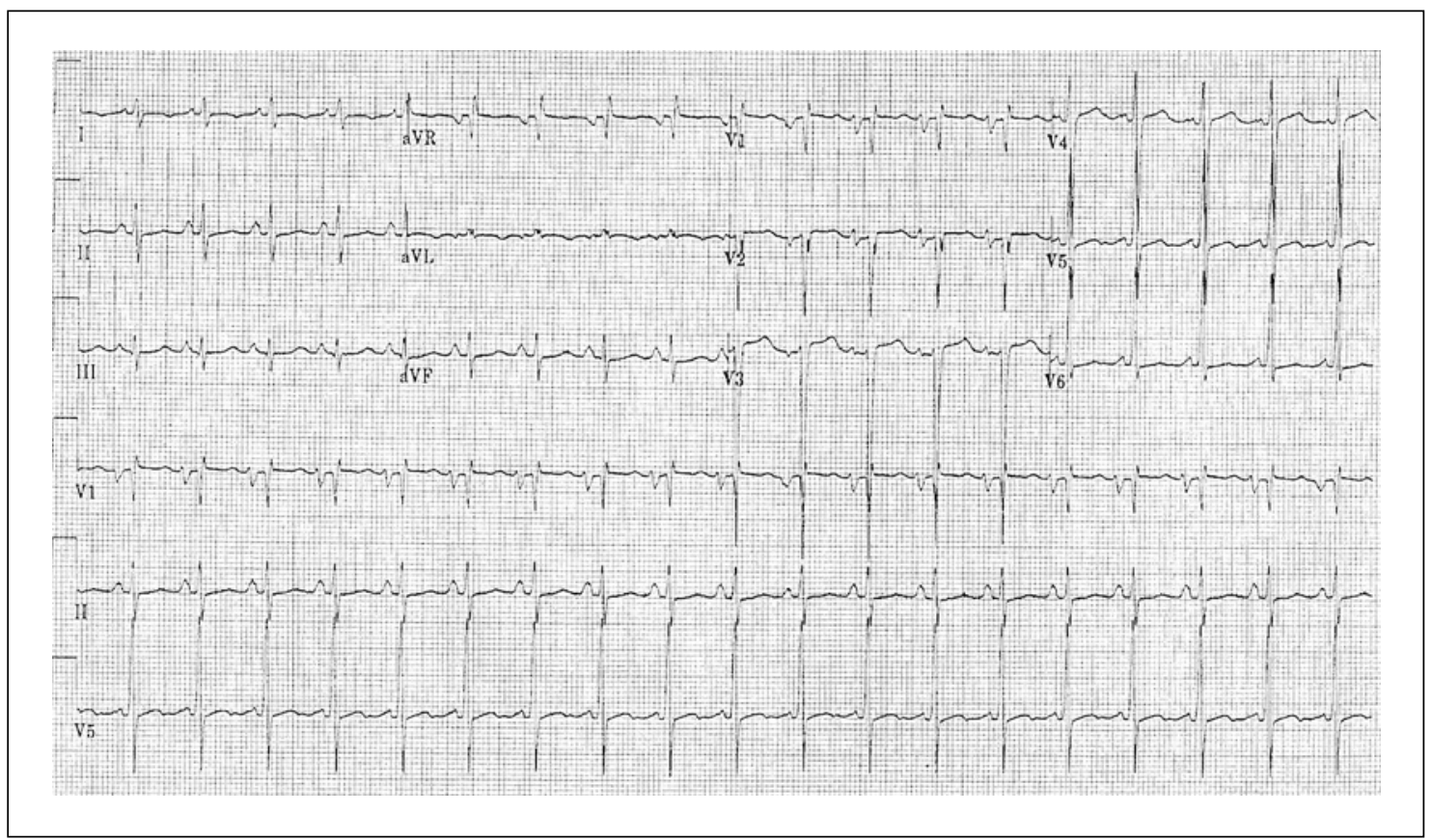

Figure 1: Initial ECG demonstrating sinus tachycardia at 116 beats/minute, with left atrial enlargement, and anterior infarction (Q-wave in V1 with delayed $R$-wave progression). 


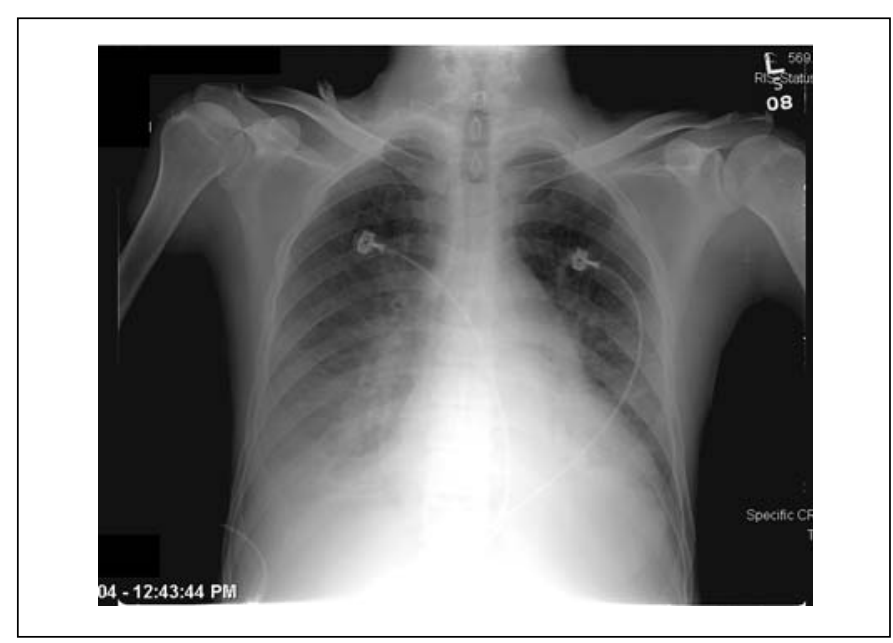

Figure 2: Portable AP chest radiograph demonstrating probable cardiomegaly with changes consistent with congestive heart failure.

He rapidly deteriorated into pulseless electrical activity. There was no palpable pulse and a regular electrical heart rate of 80-100/minute. Endotracheal intubation was performed and an extensive resuscitation attempted. A bedside transthoracic echocardiogram performed by the cardiology consultant showed near complete akinesis of his left ventricle with out any evidence of pericardial effusion, valvular dysfunction, or aortic dissection. A FAST examination failed to show any free fluid in the abdomen or aortic aneurysm. Pharmacological agents, including epinephrine, atropine, glucagon, dopamine and vasopressin, were unsuccessful at restoring circulation. Support was terminated approximately 1 hour after his deterioration. The patient's family refused a postmortem examination.

\section{DISCUSSION}

The use of beta adrenergic antagonists in the setting of cocaine toxicity incites controversy. Initial case reports of the use of propranolol are often cited in support of the safety and efficacy of this practice [6-8]. However, closer examination of one of these reports reveals that the authors abandoned the use of propranolol alone [and added clonidine] because "this has led to some rather unpleasant side effects, [such as] hyperpyrexia, dyspnea, headache and diastolic hypertension" [8].

In contrast, controlled animal models clearly demonstrate that beta adrenergic receptor antagonists exacerbate the lethal effects of cocaine $[9,10]$. Although not fully elucidated in animals, the presumed mechanism is unopposed alpha adrenergic agonism, leading to vasospasm followed by tissue ischemia and infarction. The only controlled human data involves small doses of cocaine given to patients undergoing cardiac catheterization. In two such studies, the authors demonstrated coronary artery vasospasm that was exacerbated by propranolol and relieved by phentolamine $[11,12]$. These data support the hypothesis of unopposed alpha adrenergic antagonism. Because labetolol has alpha adrenergic antagonist effects, it was also evaluated in this human cardiac catherization model. Although labetolol blunted cocaine-induced hypertension, its effects on coronary arteries were no better than placebo effects [13].

Despite these well controlled experiments, multiple authors continue to report on the use of propranolol, esmolol, and labetolol in patients with cocaine toxicity [14-17]. In one small case series, seven patients with acute cocaine intoxication were given esmolol in an attempt to control their heart rate and blood pressure [15]. Four patients improved, one was essentially unchanged, one developed significant hypotension without a change in heart rate, and the last showed an increase in blood pressure: pressure went from 200/120 $\mathrm{mm} \mathrm{Hg}$ to $230 / 180 \mathrm{~mm} \mathrm{Hg}$ and heart rate fell 36 beats/minute in pulse, possibly demonstrating unopposed alpha adrenergic agonism. The other reports either provided no data or are insufficiently documented to critically assess the utility of the drugs administered $[14,17,16]$.

Finally, a recent animal model and accompanying editorial once again call into question the safety and efficacy of beta adrenergic antagonism in cocaine toxicity $[18,19]$. In newborn sheep pretreated with propranolol, cocaine failed to alter cerebral blood flow or cerebral vascular resistance [18]. Unfortunately, in a subsequent study, the same researchers demonstrated significant differences in response to cocaine in fetal, newborn, and adult sheep [20]. Although this line of investigation is interesting and worth perusing, it is our opinion that given the obvious limitations, any data derived from the cerebral circulation of a small number of pretreated newborn sheep would be insufficient to overshadow either lethality studies in adult dogs and primates or controlled human data from the catheterization laboratory.

Based on an understanding of the pharmacology of cocaine and the data presented above, we agree with the generally accepted philosophy that beta adrenergic receptor antagonists should not be used in the setting of cocaine toxicity [21]. However, many unanswered questions remain. Most importantly, how soon after cocaine use might it be safe to administer beta adrenergic receptor antagonists if they were otherwise indicated?

This case report is neither presented to help elucidate the proposed mechanism of a cocaine-beta adrenergic receptor antagonist interaction nor to attribute causality of the patient's demise to this interaction. It is, however, presented to increase the awareness that such an interaction exists. While it may be possible to give beta adrenergic antagonists safely to patients with a history of cocaine use, it remains unclear what duration of abstinence between a patient's last cocaine use and beta adrenergic receptor antagonist administration (hours, days, or weeks) is safe and whether any benefit can be realized. Like all case reports, it is difficult to assign causality. We recognize significant limitations of this report. Ideally, a post-mortem examination would have helped to understand the pathophysiology of the patient's demise. Additionally, an echocardiogram prior to the administration of metoprolol would have been useful. The patient possibly had global hypokinesis and perhaps the tachycardia was not a continued manifestation of cocaine toxicity, but rather a compensatory 
mechanism to maintain cardiac output. If this were true, the combination of a drug with negative inotropic and chronotropic effects could have been sufficient to cause cardiovascular collapse without invoking an adverse interaction with cocaine. That being said, however, the initial ECG was neither typical of a cardiomyopathy nor a massive anterior wall infarction. And although positive, the troponin was not markedly elevated. Additionally, although the rapid recurrence of crushing chest pain is suggestive of vasospasm, it is also suggestive of aortic dissection. We believe, however, that the physical findings, cardiac echo, and FAST examination, although not definitive, helped limit the possibility of dissection. Even though there was a close temporal relationship between the patient's clinical deterioration and the metoprolol administration, we recognize that this relationship might have occurred solely by chance. Alternatively, recurrent vasoconstriction from a cocaine metabolite, with or without a metoprolol interaction, could have been responsible [22]. Despite these limitations, the biological plausibility based on pharmacological mechanisms, the existing animal and human data, and the close temporal relationship are supportive of an adverse interaction between cocaine and beta adrenergic receptor antagonists.

We encourage all clinicians to obtain a history of cocaine use prior to the administration of beta adrenergic receptor antagonists. It is the authors' opinion that either a positive history or positive urine screen for cocaine should be considered a relative if not absolute contraindication for the use of beta adrenergic receptor antagonists.

The authors have no potential financial conflicts of interest to report.

\section{REFERENCES}

1. Lange RA, Hillis LD. Cardiovascular complications of cocaine use. N Engl J Med 2001;345:351-358.

2. Brody SL, Slovis CM, Wrenn KD. Cocaine-related medical problems: Consecutive series of 233 patients. Am J Med. 1990;88:325-331.

3. Qureshi AI, Suri MF, Guterman LR, Hopkins LN. Cocaine use and the likelihood of nonfatal myocardial infarction and stroke: Data from the third national health and nutrition examination survey. Circulation. 2001;103:502-506.

4. National Quality Measures Clearinghouse: Acute myocardial infarction: percent of patients without beta blocker contraindications who received a beta blocker within 24 hours after hospital arrival. Accessed September 1, 2007. Available at: http://www.qualitymeasures.ahrq.gov/summary/summary .aspx?doc_id=6054

5. Joint Commission on Accreditation of Healthcare Organizations. Beta Blockers For Acute Myocardial Infarction. Accessed 2/1/07. Available at: http://www.jointcommission.org/ NR/rdonlyres/AB92B013-B9A7-48AC-8AC6-759410D6E791/0/ COMMITBetaBlockerFACTSheet.pdf
6. Rappolt RT, Gay G, Inaba DS, Rappolt NR. Propranolol in cocaine toxicity. Lancet. 1976;2(7986):640-641.

7. Rappolt RT, Gay GR, Inaba DS. Propranolol: a specific antagonist to cocaine. Clin Toxicol. 1977;10:265-271.

8. Rappolt RT Sr, Gay G, Inaba DS, Rappolt N, Rappolt RT Jr. Use of Inderal (propranolol-Ayerst) in I-a (early stimulative) and I-b (advanced stimulative) classification of cocaine and other sympathomimetic reactions. Clin Toxicol. 1978;13:325-332.

9. Guinn MM, Bedford JA, Wilson MC. Antagonism of intravenous cocaine lethality in nonhuman primates. Clin Toxicol. 1980; $16: 499-508$.

10. Catravas JD, Waters IW. Acute cocaine intoxication in the conscious dog: Studies on the mechanism of lethality. J Pharmacol Exp Ther. 1981;217:350-356.

11. Lange RA, Cigarroa RG, Flores ED, McBride W, Kim AS, Wells PJ, Bedotto JB, Danziger RS, Hillis LD. Potentiation of cocaine-induced coronary vasoconstriction by beta-adrenergic blockade. Ann Intern Med. 1990;112:897-903.

12. Lange RA, Cigarroa RG, Yancy CW,Jr, Willard JE, Popma JJ, Sills MN, McBride W, Kim AS, Hillis LD. Cocaine-induced coronary-artery vasoconstriction. $N$ Engl J Med.

1989;321:1557-1562.

13. Boehrer JD, Moliterno DJ, Willard JE, Hillis LD, Lange RA. Influence of labetalol on cocaine-induced coronary vasoconstriction in humans. Am J Med. 1993;94:608-610.

14. Gay GR, Loper KA. The use of labetalol in the management of cocaine crisis. Ann Emerg Med. 1988;17:282-283.

15. Sand IC, Brody SL, Wrenn KD, Slovis CM. Experience with esmolol for the treatment of cocaine-associated cardiovascular complications. Am J Emerg Med. 1991;9:161-163.

16. Merigian KS, Park LJ, Leeper KV, Browning RG, Giometi R. Adrenergic crisis from crack cocaine ingestion: report of five cases. J Emerg Med. 1994;12:485-490.

17. Blaho K, Winbery S, Park L, Gresham HW. Cocaine use and acute coronary syndromes. Lancet. 2001;358(9290):1368.

18. O'Brien TP, Pane MA, Traystman RJ, Gleason CA. Propranolol blocks cocaine-induced cerebral vasodilation in newborn sheep. Crit Care Med. 1999;27:784-789.

19. Leikin JB. Cocaine and beta-adrenergic blockers: a remarriage after a decade-long divorce? Crit Care Med.

1999;27:688-689.

20. Robinson R, Iida H, O’Brien TP, Pane MA, Traystman RJ, Gleason CA. Comparison of cerebrovascular effects of intravenous cocaine injection in fetal, newborn, and adult sheep. Am J Physiol Heart Circ Physiol. 2000;279:H1-6.

21. Albertson TE, Dawson A, de Latorre F, Hoffman RS, Hollander JE, Jaeger A, Kerns WR 2nd, Martin TG, Ross MP. TOX-ACLS: toxicologic-oriented advanced cardiac life support. Ann Emerg Med. 2001;37(4 Suppl):S78-90.

22. Brogan WC 3rd, Lange RA, Glamann DB, Hillis LD. Recurrent coronary vasoconstriction caused by intranasal cocaine: possible role for metabolites. Ann Intern Med. 1992; $116: 556-561$. 